\section{Editor-in-Chief \\ Barbara McLain - (retired Prof.) \\ University of Hawaii, USA}

The Israeli Journal of Aquaculture (IJA) is an interdisciplinary journal that is dedicated to sharing new research and tested applications of aquaculture

The IJA is devoted to scholarly articles for improved aquaculture practices and related industries

The IJA is a peer-reviewed, open-access, electronic journal

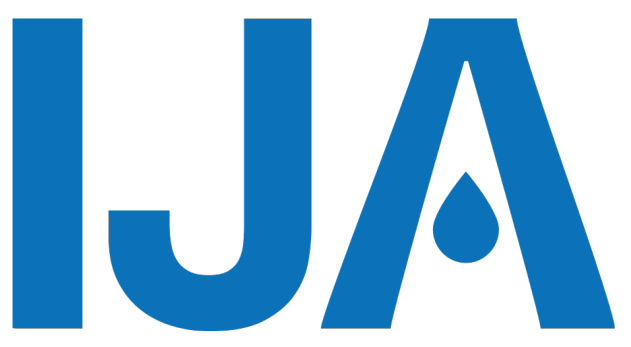

\section{The () Israeli Journal of Aquaculture}

An interdisciplinary online Open Access scientific journal

Published by the

\section{AquacultureHub}

A non-profit organization 501c3

http://www.aquaculturehub.org

in partnership with the

\section{University of Hawaii at Manoa} Library

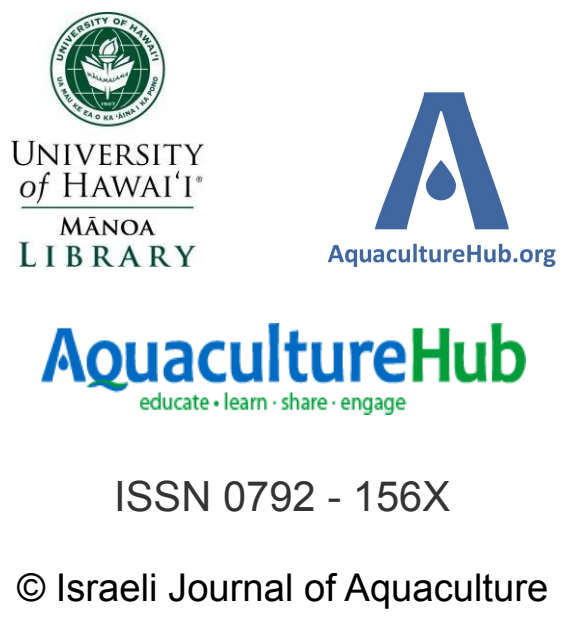




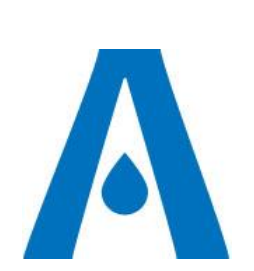

Produced by the AquacultureHub non-profit Foundation the IJA is an open-access, scientific journal, published on http://www.aquaculturehub.org/group/israelijournalofaq uaculturebamidgehija

To read papers free of charge, please register online at the above website.

Sale of IJA papers is strictly forbidden.

\title{
Discontinuous Administration of $\beta$-glucan is Effective for Preventing Immune Fatigue in Litopenaeus vannamei
}

\author{
Luo $Z^{1, a}$, Guo J2,a, Hao $S^{1}$, Zhang $Z^{1}$, Tang $\mathrm{H}^{1,3}$, Wu $\mathrm{H}^{1}$, Jiang $\mathrm{J}^{1}$, \\ Ye $\mathbf{G}^{4}$, Feng $\mathrm{S}^{4}$, Bai $\mathrm{X}^{1 *}$
}

\author{
${ }^{1}$ Tianjin Fishery Research Institute, 442 Jiefangnan Road, Tianjin 300221, China \\ ${ }^{2}$ Zhejiang Institute of Freshwater Fisheries, Huzhou, 313001, China \\ ${ }^{3}$ College of Fisheries, Tianjin Agricultural University, Tianjin, 300384, China \\ ${ }^{4}$ Prevention and Cure Center for Aquatic Animal Disease in Tianjin, 442 \\ Jiefangnan Road, Tianjin 300221, China.
}

Keywords: $\beta$-glucan; Litopenaeus vannamei growth; immune fatigue; immune response

\begin{abstract}
$\beta$-glucan is an effective, available immunostimulant that has been successfully used to improve the immune defense of shrimp against pathogenic infection. However, the long-term continuous use of $\beta$-glucan can lead to immune fatigue, and intermittent feeding may be an effective way of avoiding this phenomenon. A 60-day growth trial was conducted to compare the effects of different feeding strategies of diets containing $200 \mathrm{mg} / \mathrm{kg} \beta$-glucan on the growth and immune system of the Pacific white shrimp Litopenaeus vannamei. The results showed that either continuous feeding or intermittent feeding of diets containing $200 \mathrm{mg} / \mathrm{kg} \beta$-glucan did not promote the growth of $L$. vannamei. However, the levels of superoxide dismutase, alkaline phosphatase, and acid phosphatase in the hepatopancreas of $L$. vannamei in the intermittent feeding group were significantly higher than those in the control and continuous feeding groups. Expression levels of the genes encoding LPS/ $\beta$-glucan binding protein, superoxide dismutase, lysozyme, penaeid in-3a, and catalase were also significantly upregulated in the intermittent feeding group, whereas most of the immune parameters in the continuous feeding group were not significantly different from those of the control group. After artificial infection with Vibrio parahaemolyticus, the average mortality rates in the control group, the continuous feeding group, and the intermittent feeding group were $76.67 \%$, $78.89 \%$, and $45.56 \%$, respectively. The results indicated that the addition of 200 $\mathrm{mg} / \mathrm{kg} \beta$-glucan to the diet did not promote the growth of $L$. vannamei, but the strategy of intermittent feeding effectively prevented immune fatigue and enhanced disease resistance, perhaps by increasing nonspecific immunity in $L$. vannamei.
\end{abstract}

\footnotetext{
* Corresponding author. Tel: +862288251021; Fax: +862288252084

email: bxh123bxh@163.com

a These authors contributed equally to this work
} 


\section{Introduction}

Pacific white shrimp Litopenaeus vannamei is widely cultivated due to its strong adaptability, fast growth rate, and high nutritional value, rendering it one of the topthree shrimp species in the world in terms of aquaculture production. However, the commercial production of $L$. vannamei has been hampered by several pathogens, including: the bacterial pathogens Vibrio parahaemolyticus, Vibrio harveyi, Vibrio owensii, and Vibrio campbellii (Tran et al., 2013; Lee et al., 2015; Kondo et al., 2015; Liu et al., 2015; Dong et al., 2017) and by viral pathogens, such as white spot syndrome virus (WSSV), Taura syndrome virus (TSV), covert mortality nodavirus (CMNV) (Walker and Mohan, 2009; Zhang et al., 2014), and by parasites, such as Enterocytozoon hepatopenaei (Tangprasittipap et al., 2013). Disease has become the most important factor hindering the development of the L. vannamei industry (Hsieh et al., 2013). As with all crustaceans, shrimp lack an acquired adaptive immune system, and their defense against pathogen infections relies primarily on innate immunity (Bachere et al., 1995). The use of immunostimulants to enhance innate immunity in L. vannamei, and help them resist pathogen invasion is an effective way to achieve such enhancement (Wang et al., 2008).

$\beta$-glucan, which comprises glucose units linked via $\beta-1,3$ or $\beta-1,6$ glycosidic linkage, is one of the most effective immunostimulants available and has been successfully applied to improve the immune defenses of crustaceans against viral, bacterial, and parasitic infections (Chang et al., 2010). Studies have also shown that the immunostimulatory effects of $\beta$-glucan are closely related to the duration of its use. The stimulatory effects of $\beta$-glucan are likely to be short term (Sakai, 1999), given that the long-term continuous use of $\beta$-glucan can lead to immune fatigue in L. vannamei (Bai et al., 2010; Sajeevan et al., 2009). Thus, there is a need to avoid immune fatigue caused by $\beta$-glucan feeding in L. vannamei, and intermittent feeding could be one such approach. Therefore, in this study we compared the effects of long-term continuous feeding and intermittent feeding of diets containing $\beta$-glucan on the growth and immunity of $L$. vannamei, to determine whether intermittent feeding could effectively eliminate immune fatigue in this species.

Diets.

\section{Materials and Methods}

$\beta$-glucan was added to a basal diet at a level of $200 \mathrm{mg} / \mathrm{kg}$. The basal diet was prepared according to the method of Zhao et al. (2012) (Table 1). The nutrients in the basal diet included $40 \%$ crude protein, $8 \%$ crude fat, and $13 \%$ ash. The feed ingredients were crushed and passed through a 60-mesh sieve and then thoroughly mixed. Fish oil and water were added to the mixture to produce a stiff dough. The dough was then extruded and cut into pellets $(1 \mathrm{~mm})$. After drying at $45^{\circ} \mathrm{C}$, the feed was stored at $-20^{\circ} \mathrm{C}$ until use. Table 1. Composition of the basal diet for Litopenaeus vannamei

\begin{tabular}{ll}
\hline Ingredient & Composition $(\mathrm{g} / \mathrm{kg})$ \\
\hline Fish meal & 300 \\
Soy protein concentrate & 300 \\
Corn starch & 280 \\
Fish oil & 50 \\
Soybean lecithin & 15 \\
Choline chloride & 10 \\
Calcium phosphate & 15 \\
Vitamin premix & 20 \\
Mineral premix & 5 \\
a-cellulose & 5 \\
\hline
\end{tabular}

Experimental animals.

L. vannamei (initial mass $0.87 \pm 0.23 \mathrm{~g}$ ) were supplied by Tianjin Tianfeng Aquaculture Co., Ltd. After being transported to the laboratory, the animals were kept in a $600-\mathrm{L}$ round tank containing $300 \mathrm{~L}$ of water and allowed to adapt to their new conditions for 14 days. The shrimp were fed the basal diet during the adaptation period. Detection of pathogens, such as CMNV, E. hepatopenaei, shrimp hemocyte iridescent virus, infectious hypodermal and hematopoietic necrosis virus, WSSV, TSV, and acute 
hepatopancreatic necrosis disease-causing bacteria, was carried out during the adaptation period. Specific pathogen-free shrimp were then selected for the study.

Feeding trial.

L. vannamei were randomly divided into three groups, with three replicates per group and 200 shrimp per replicate. Shrimp in Group I were fed the basal diet; those in Group II were continuously fed a diet containing $\beta$-glucan; and shrimp in Group III were fed a diet containing $\beta$-glucan for 15 days and then a basal diet for 15 days; this continued for the length of the study. The trial period was 60 days, during which, the shrimp were fed four times a day, and the daily feeding amount was $6 \%-10 \%$ of the body weight of the shrimp. Any food remnants and excrement were removed before feeding. The culture conditions were: water temperature $27 \pm 2^{\circ} \mathrm{C}$, salinity $25 \pm 1$, pH $8.0 \pm 0.2$, and dissolved oxygen $>6.0 \mathrm{mg} / \mathrm{L}$, by continuous aeration throughout the trial period. One-third of the water was changed once a day. At the end of the trial period, 30 shrimp were randomly taken from each replicate in each group for measurement of body weight. Weight gain rates (WGR) were calculated, and survival rates (SR) were determined for each group using Equations 1 and 2, respectively:

WGR $=100 \% \times($ final body weight - initial body weight $) /($ initial body weight $)$ [1]

$\mathrm{SR}=100 \% \times($ final amount of shrimp)/(initial amount of shrimp) [2]

Sample collection.

On the 60th day of the feeding trial, the hepatopancreas was randomly collected from each of nine shrimp from each replicate in each group; the hepatopancreas from three shrimp were mixed to give one sample, which was then divided into two portions. One portion was placed in an RNA preservation solution and stored at $-80^{\circ} \mathrm{C}$ for quantitative real-time (qRT-)PCR analysis. The other portion was diluted with $9 \times$ phosphate buffer solution $(\mathrm{pH} 6.4,0.1 \mathrm{M})$, homogenized, then centrifuged at $3000 \mathrm{~g}$ for $15 \mathrm{~min}$ at $4^{\circ} \mathrm{C}$. The supernatant was then used to determine the immune parameters.

Quantitative real-time PCR analysis.

RNA was extracted using RNAprep Pure Tissue Kit (Tiangen, China) according to the instruction manual. cDNA was generated from RNA using a PrimeScript ${ }^{\mathrm{TM}}$ Master Mix kit (Takara, Japan) for qRT-PCR. The primers used are shown in Table 2 . The reaction system comprised $0.5 \mu \mathrm{L}$ of each forward and reverse primer $(10 \mu \mathrm{mol} / \mathrm{L}), 10 \mu \mathrm{L}$ of $2 \times$ mix, $1 \mu \mathrm{L}$ of template, and $8 \mu \mathrm{L}$ of $\mathrm{dd} \mathrm{H}_{2} \mathrm{O}$. The thermal profile was $95^{\circ} \mathrm{C}$ for $3 \mathrm{~min}, 45$ cycles of $95^{\circ} \mathrm{C}$ for $20 \mathrm{~s}, 55^{\circ} \mathrm{C}$ for $20 \mathrm{~s}$, and $72^{\circ} \mathrm{C}$ for $30 \mathrm{~s}$. Each sample was run in triplicate. Relative gene expression levels were determined by the comparative threshold cycle method $\left(2^{-\Delta \Delta} \mathrm{ct}\right)$ with the gene encoding $\beta$-actin used as the reference gene (Zhang et al., 2012).

Table 2. Sequences of primers used in qRT-PCR

\begin{tabular}{lcc}
\hline \multirow{2}{*}{ Gene name } & \multicolumn{2}{c}{ Sequence $\left(5^{\prime} \rightarrow 3^{\prime}\right)$} \\
\cline { 2 - 3 } & Forward & Reverse \\
\hline Superoxide dismutase & CCACGAGACCACCTACAAC & AGCGAGGGCAGTGATTC \\
Penaedin-3a & GGACTACGGCATCTTCCAGA & ATCGGACATCAGATCGGAAC \\
Catalase & CACCCTTCGTGAGACCTTTG & AATATCCCTTCCCACGTGAC \\
$\beta$-actin & TCAAGTGGCGATACCCCTC & TCTGCTCCACCTCAGCAAAG \\
$\beta$-glucan binding protein & CCACGAGACCACCTACAAC & AGCGAGGGCAGTGATTC \\
LPS $\beta$-glucan binding protein & ACGAGAACGGACAAGAAGTG & TCAGCATAGAAGCCATCAGG \\
\hline
\end{tabular}

Immune parameter assay.

The amount of superoxide dismutase (SOD), lysozyme (LZM), alkaline phosphatase (AKP), and acid phosphatase (ACP) in the hepatopancreas of L. vannamei were determined using kits according to the manufacturer's instructions (Jiancheng, China).

Artificial infection trial.

On the 60th day, $30 \mathrm{~L}$. vannamei were randomly selected from each replicate in each group for artificial infection based on the method of Trans et al. (2013). Vibrio parahaemolyticus isolate 20170630-4 was cultured in Tryptone Soya broth for $36 \mathrm{~h}$ at $37^{\circ} \mathrm{C}$ and shaken at $150 \mathrm{r} / \mathrm{min}$. The bacteria were collected by centrifugation at $6000 \mathrm{~g}$ for $10 \mathrm{~min}$. The final concentration of the bacteria was adjusted to $2.5 \times 10^{5} \mathrm{cfu} / \mathrm{mL}(2 \times$ median lethal dose) in an immersion challenge test with $0.7 \% \mathrm{NaCl}$ solution as a 
negative control. After artificial infection, shrimp were fed the basal diet. Dead shrimp were removed as soon as possible, and the time of death and the number of deaths were recorded. The infection trial lasted for 7 days.

Statistical analysis.

All experimental data were expressed as mean \pm standard deviation. One-way ANOVA was performed using SPSS 17.0 software, and Duncan's multiple comparison was used to assess the differences between Groups. The significance level was set at $P=$ 0.05 .

\section{Results}

After 60 days of cultivation, the final body weight and WGR of L. vannamei in Group III were not significantly different from those in Groups I and II, whereas the SR in Group III was significantly higher than that in Groups I and II (Table 3). There was no significant difference in WGR and SR between Group I and Group II (Table 3).

Table 3. Growth performance and survival rate of Litopenaeus vannamei in the different feedingstrategy groups

\begin{tabular}{|c|c|c|c|}
\hline \multirow{2}{*}{ Index } & Group I & Group II & Group III \\
\hline & Control & Continuous feeding & Intermittent feeding \\
\hline Initial body weight (g) & $0.86 \pm 0.23^{a}$ & $0.88 \pm 0.12^{a}$ & $0.87 \pm 0.31^{a}$ \\
\hline Final body weight (g) & $13.10 \pm 3.83^{a}$ & $13.52 \pm 3.44^{a}$ & $14.14 \pm 5.51^{\mathrm{a}}$ \\
\hline Weight gain rates $(\%)$ & $1423.16 \pm 445.29^{a}$ & $1431.18 \pm 445.29^{a}$ & $1488.65 \pm 618.85^{a}$ \\
\hline survival rates $(\%)$ & $79.33 \pm 2.87^{a}$ & $76.17 \pm 4.50^{a}$ & $87.67 \pm 2.24^{b}$ \\
\hline
\end{tabular}

Values in a row with different superscripts differed significantly $(P<0.05)$.

There were no significant differences in the levels of SOD, LZM, AKP, or ACP in the hepatopancreas of $L$. vannamei between Groups I and II (Table 4). The levels of SOD, $A K P$, and ACP in the hepatopancreas of $L$. vannamei in Group III were significantly higher than those in Groups I and II, whereas the amount of LZM was significantly lower than that in Groups I and II (Table 4).

Table 4. Biochemical indices in the hepatopancreas of Litopenaeus vannamei in the different feeding-strategy groups

\begin{tabular}{lcccc}
\hline \multirow{2}{*}{ Group (feeding strategy) } & \multicolumn{4}{c}{ Biochemical index } \\
\cline { 2 - 5 } & $S O D(U / m g)$ & $L Z M(U / m g)$ & $A K P(U / g)$ & $A C P(U / g)$ \\
\hline Group I (control) & $26.17 \pm 0.69^{\mathrm{a}}$ & $7.09 \pm 0.62^{\mathrm{a}}$ & $9.28 \pm 0.63^{\mathrm{a}}$ & $8.49 \pm 0.53^{\mathrm{a}}$ \\
Group II (continuous) & $23.61 \pm 1.27^{\mathrm{a}}$ & $6.18 \pm 0.37^{\mathrm{a}}$ & $8.9 \pm 1.71^{\mathrm{a}}$ & $8.80 \pm 1.26^{\mathrm{a}}$ \\
Group III (intermittent) & $30.11 \pm 1.22^{\mathrm{b}}$ & $3.94 \pm 0.58^{\mathrm{b}}$ & $14.84 \pm 0.48^{\mathrm{b}}$ & $11.51 \pm 0.37^{\mathrm{b}}$ \\
\hline
\end{tabular}

Values with different superscripts differed significantly $(P<0.05)$.

The results of qRT-PCR showed that compared with Group I, the expression of BGBP was significantly upregulated and that of PEN3a was significantly downregulated, whereas the expression levels of $\angle G B P, S O D, L Z M$, and CAT did not change, in the hepatopancreas of $L$. vannamei from Group II. By contrast, the expression levels of $\angle G B P, S O D, L Z M, P E N 3 a$ and CAT in the hepatopancreas of $L$. vannamei in Group III were significantly upregulated compared with Group I (Fig. 1).

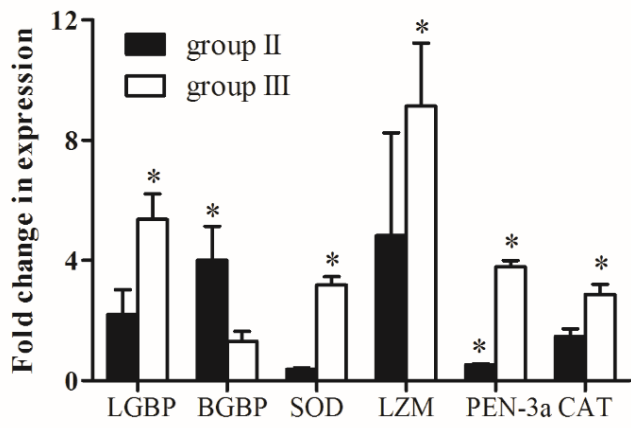

Fig. 1. Fold changes in the expression of immune-related genes in the hepatopancreas of Litopenaeus vannamei in the different feeding-strategy groups.

After the challenge with $V$. parahaemolyticus isolate 20170630-4, dead shrimp were found from Day 1 . The main symptoms were: anorexia, empty stomach and gut, lightcolored hepatopancreas, and soft shells. The cumulative mortality rates in Group I, 
Group II, Group III, and a negative control group were $76.67 \%, 78.89 \%, 45.56 \%$, and $3.33 \%$, respectively (Fig. 2 ).

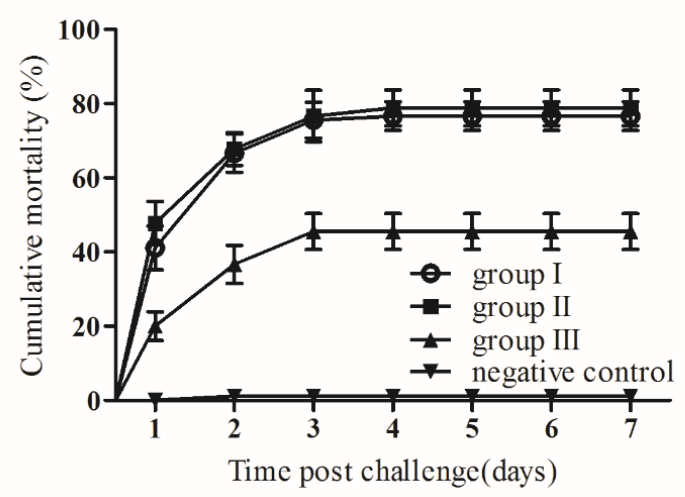

Fig. 2. Cumulative mortality of Litopenaeus vannamei in the different feeding-strategy groups after infection with Vibrio parahaemolyticus

\section{Discussion}

Controversy over the growth-promoting effects of $\beta$-glucan on aquatic animals still exists. For example, Zhao et al. (2012) reported that continuous feeding with a diet containing $250 \mathrm{mg} / \mathrm{kg} \beta$-glucan to $L$. vannamei for 84 days promoted growth. By contrast, in the current study, L. vannamei were fed a diet containing $200 \mathrm{mg} / \mathrm{kg} \beta$-glucan for 60 days, and neither continuous feeding nor intermittent feeding showed any growth-promoting effects, in agreement with the results of Ye et al. (2011). This discrepancy might be caused by the different amounts of $\beta$-glucan added and different feeding times. Moreover, it is unclear how $\beta$-glucan positively impacts growth. Dalmo and Bogwald (2008) hypothesized that the growth-promoting effects of $\beta$-glucan are indirectly caused by a reduced incidence of disease, which can affect the growth of aquatic animals. Therefore, more studies are needed to elucidate the mechanisms behind the growthpromoting effects of $\beta$-glucan in aquatic animals.

The effect of $\beta$-glucan as an immunostimulant on the immunity of $L$. vannamei is closely related to the dose used. Low doses do not enhance immunity, whereas high doses can cause immunosuppression (Sajeevan et al., 2009). According to previous research (Bai et al., 2010; Sajeevan et al., 2009; Wang et al., 2008), the addition of $0.2 \% \beta$-glucan to the diet enhanced the immunity of $L$. vannamei. Moreover, long-term feeding of $\beta$-glucan-containing diets even with a suitable dose can lead to immunosuppression in L. vannamei (Chang et al., 2000). The culture period of $L$. vannamei is several months. To reduce the occurrence of diseases, it is necessary for $L$. vannamei to have a high immunity level throughout the culture period. Therefore, it is necessary to determine how to avoid immune fatigue in L. vannamei caused by longterm feeding of $\beta$-glucan.

The current results showed that SOD, AKP, and ACP activities of $L$. vannamei in Group III were significantly higher than those in Groups I and II (Table 4).

Moreover, the expression levels of SOD, LZM, PEN3a, and CAT were also significantly upregulated (Fig. 1). The levels of SOD, LZM, AKP, and ACP in the hepatopancreas of shrimp in Group II were not significantly different from those in Group I (Table 4).

Similarly, at the RNA level, the expression levels of SOD, CAT, and $L Z M$ were not upregulated, whereas ABP expression was significantly downregulated (Fig. 1). LZM can hydrolyze bacterial cell walls and acts as a nonspecific innate immunity molecule against invading bacterial pathogens. ACP and AKP are involved in the degradation of phagocytized pathogens, accelerating hydrolysis, and transphosphorylation, preventing the growth and multiplication of pathogens in the host. They also have an important role in the defense reaction in crustaceans. CAT is a major primary immune defense component that works primarily to catalyze the decomposition of $\mathrm{H}_{2} \mathrm{O}_{2}$ to $\mathrm{H}_{2} \mathrm{O}$. SOD can scavenge superoxide $\left(\mathrm{O}_{2}^{-}\right)$and hydrogen peroxide $\left(\mathrm{H}_{2} \mathrm{O}_{2}\right)$. Thus, CAT and SOD are important antioxidant enzymes. The results of this study indicate that the intermittent feeding pattern enhanced the immune system and antioxidant defense system in $L$. vannamei. These phenomena were not observed in Group II, which was probably related to immune fatigue. Our results were consistent with those of Bai et al. (2010), who 
showed that phenoloxidase (PO) and SOD in hepatopancreas began to decrease on Days 35 and 27, respectively, after continuous feeding with a diet containing $0.2 \% \beta$-glucan. In addition, other results found that after 40 days of continuous feeding of a diet containing $0.2 \% \beta$-glucan to $L$. vannamei, the number of blood cells was lower than in the control group (Sajeevan et al. 2009). The authors suggest that this was due to immune fatigue caused by a continuous intake of $\beta$-glucan.

Although the specific mechanism for immune fatigue remains unclear, studies have shown that $\beta$-glucan can bind to pattern recognition proteins, such as $\beta$-glucan-binding protein ( $\beta G B P$ ) and lipopolysaccharide and $\beta$-glucan binding protein (LGBP) to form a protein-recognition complex. This complex then reacts with and induces the degranulation of, both granular and semigranular hemocytes. Long-term feeding with $\beta$ glucan might lead to excessive degranulation, reduced hemocyte quantity, and immune system exhaustion (Bai et al., 2010). BGBP and LGBP are important pattern recognition receptors, with roles in activating the immune system in L. vannamei. Commonly, upregulation of these two genes also upregulates nonspecific immune parameters, such as PO and SOD. However, in Group II, LGBP was upregulated 4.01 times, whereas the expression levels of downstream genes, such as SOD, LZM, and CAT, were not. Whether the expressions of these genes are associated with immune fatigue needs further study.

Intermittent feeding and feeding with alternative immunostimulants are common strategies for avoiding immune fatigue due to the long-term use of immunostimulants. Intermittent feeding is more cost-effective than feeding with alternative immunostimulants, but the frequency of intermittent feeding is critical. Previous studies showed that feeding Indian white shrimp Fenneropenaeus indicus with diets containing $0.2 \%$ glucan once every 7 days resulted in higher SRs than feeding daily, once every 2 days, once every 5 days, and once every 10 days (Bai et al., 2009). The abundant plankton in the culture ponds may also form part of the diet of $L$. vannamei, and some shrimp may consume only plankton on the first day, without taking any artificial feed. Adoption of the best feeding strategy reported by Bai et al. (administration once every 7 days) may thus mean that some shrimp do not consume any glucan. We therefore changed the feeding frequency to once every 15 days. Previous studies also showed a decline in nonspecific immunity only after continuous feeding of diets containing glucan for at least 3 weeks. In this case, the current feeding frequency may have been preferable to that reported by Bai et al., by ensuring sufficient intake of glucan by all shrimp. The results also showed that this feeding frequency effectively increased the SR of $L$. vannamei, while this may be further optimized in future work.

The levels of LZM, ACP, AKP, CAT, and SOD in crustaceans are closely related to their capacity to resist disease and environmental stress. The current results showed that long-term intermittent feeding with $\beta$-glucan effectively improved the SR of $L$. vannamei. In addition, after infection by $V$. parahaemolyticus, $L$. vannamei in Group III also showed lower mortality, indicating that long-term intermittent feeding of $\beta$-glucan could increase the SR of L. vannamei, possibly by increasing nonspecific immunity in the shrimp. Although intermittent feeding of $\beta$-glucan did not provide $100 \%$ protection against $V$. parahaemolyticus in the artificial infection trial, $\beta$-glucan might exert anti-infection effects by increasing nonspecific immunity in L. vannamei, such that its anti-infection ability might be equally effective against other pathogens. Therefore, this feeding strategy will help improve the SR of $L$. vannamei in the face of possible invasion by different pathogens during its aquaculture. However, longer trials will be necessary to make better use of $\beta$-glucan to improve the SR of $L$. vannamei, the culture period of which is $120-150$ days.

\section{Acknowledgments}

The study was supported by the Open Research Fund Program of the Key Laboratory of Healthy Culture of Freshwater Fishery, Ministry of Agriculture, P. R. China (2016ZJK07), Project for Tianjin Fisheries Innovative Team (ITTFR2017008), Projects for Tianjin Science and Technology Plan (18ZXBFNC00040), and the Foundation of Tianjin Fishery Research Institute (scyjs201904). 


\section{References}

Bachere E., Mialhe E., Noel D., Boulo V., Morvan A. and J. Rodriguez, 1995. Knowledge and research prospects in marine mollusk and crustacean immunology. Aquaculture, 132: 17-32.

Bai N., Zhang W. B., Mai K. S., Wang X. J., Xu W. and H. M. Ma, 2010. Effects of discontinuous administration of $\beta$-glucan and glycyrrhizin on the growth and immunity of white shrimp Litopenaeus vannamei. Aquaculture, 306: 218-224.

Chang C. F., Chen H. Y., Su M. S. and I. C. Liao, 2000. Immunomodulation by dietary $\beta-1,3-$ glucan in the brooders of the black tiger shrimp Penaeus monodon. Fish Shellfish Immunol, 10: 505-514.

Chang J., Zhang W. B., Mai K. S., Ma H. M., Liufu Z. G., Wang X. J., Ai Q. H. and W. Xu, 2010. Effects of dietary b-glucan and glycyrrhizin on non-specific immunity and disease resistance of white shrimp, Litopenaeus vannamei (Boone) challenged with Vibrio alginolyticus. Aquacult Res, 42(8): 1101-1109.

Dalmo R. A. and J. Bøgwald, 2008. $\beta$-glucans as conductors of immune symphonies. Fish Shellfish Immunol, 25: 384-396.

Dong X., Wang H. L., Xie G. S., Zou P., Guo C., Liang Y. and J. Huang, 2017. An isolate Vibrio campbellii carrying the pir ${ }^{\mathrm{VP}}$ gene causes acute hepatopancreatic necrosis disease. Emerg Microbes Infect, 6(1): e2.

Harada M., 1991. Protein phosphatase activity of calf intestinal alkaline phosphatase. Experientia, 37: 547-548.

Hsieh S. L., Wu C. C., Liu C. H. and J. L. Lian, 2013. Effects of the water extract of Gynura bicolor (Roxb. \& Willd.) DC on physiological and immune responses to Vibrio alginolyticus infection in white shrimp (Litopenaeus vannamei). Fish Shellfish Immunol, 35:18-25.

Kondo H., Van P. T., Dang L. T. and I. Hirono, 2015. Draft genome sequence of non-Vibrio parahaemolyticus acute hepatopancreatic necrosis disease strain KC13.17.5, isolated from diseased shrimp in Vietnam. Genome Announc, 3(5): e00978-15.

Lazado C. C., Caipang C. M. A., Gallage S., Brinchmann M. F. and V. Kiron, 2010. Responses of Atlantic cod Gadus morhua head kidney leukocytes to phytase produced by gastrointestinal-derived bacteria. Fish Physiol Biochem, 36: 883-891.

Lee C. T., Chen I. T., Yang Y. T., Ko T. P., Huang Y. T., Huang J.Y., Huang M. F., Lin S. J., Chen C. Y., Lin S. S., Lin S. S., Lightner D. V., Wang H. C., Wang A. H. J., Wang H. C., Hor L. I. and C. F. Lo, 2015. The opportunistic marine pathogen Vibrio parahaemolyticus becomes virulent by acquiring a plasmid that expresses a deadly toxin. PNATL ACAD SCI USA, 112(34): 10798-10803.

Liu L. Y, Xiao J. Z, Xia X, M., Pan Y. J., Yan S. L. and Y. J. Wang, 2015. Draft genome sequence of Vibrio owensii strain $\mathrm{SH}-14$, which causes shrimp acute hepatopancreatic necrosis disease. Genome Announc, 3(6): e01395-15.

López N., Cuzon G., Gaxiola G., Taboada G., Valenzuela M., Pascual C., Sánchez A. and C. Rosas, 2003. Physiological, nutritional, and immunological role of dietary $\beta 1$ 3 glucan and ascorbic acid 2-monophosphate in Litopenaeus vannamei juveniles. Aquaculture, 224: 223-243.

Sajeevan T. P., Rosamma P. and I. S. Bright Singh, 2009. Dose/frequency: A critical factor in the administration of glucan as immunostimulant to Indian white shrimp Fenneropenaeus indicus. Aquaculture, 287: 248-252.

Sakai M., 1999. Current research status of fish immunostimulants. Aquaculture,172: 6392.

Tangprasittipap A., Srisala J., Chouwdee S., Somboon M., Chuchird N., Limsuwan C., Srisuvan T., Flegel T. W., and K. Sritunyalucksana, 2013. Themicrosporidian Enterocytozoon hepatopenaei is not the cause of white feces syndrome in Whiteleg shrimp Penaeus (Litopenaeus) vannamei. BMC Vet Res, 9(1):1-10.

Tran L., Nunan L., Redman R. M., Mohney L. L., Pantoja C. R., Fitzsimmons K. and D. V. Lightner, 2013. Determination of the infectious nature of the agent of acute hepatopancreatic necrosis syndrome affecting penaeid shrimp. Dis Aquat Organ, 105(1): 45-55. 
Walker P. J. and C. V. Mohan, 2009. Viral disease emergence in shrimp aquaculture: origins, impact and the effectiveness of health management strategies. Rev. Aquac, 2:125-154.

Wang W. N., Wang Y., and A. L. Wang, 2006. Effect of supplemental L-ascorbyl-2polyphosphate (APP) in enriched live food on the immune response of Penaeus vannamei exposed to ammonia-N. Aquaculture, 256: 552-557.

Wang Y. C., Chang P. S. and H. Y. Chen, 2008. Differential time-series expression of immune-related genes of Pacific white shrimp Litopenaeus vannamei in response to dietary inclusion of $\beta-1,3-$ glucan. Fish Shellfish Immunol, 24: 113-121.

Ye J. D., Wang K., Li F. D. and Y. Z. Sun, 2011. Effects of Long-Term Dietary Administration of $\beta$-glucan on Tissue Enzyme Activity and Disease Resistance in Common Carp, Cyprinus carpio. Isr. J. Aquacult.-Bamidgeh, AquacultureHub, IIC:63.2011.664, 6 pages.

Zhang Q. L., Liu Q., Liu S., Yang H. L., Liu S., Zhu L. L., Yang B., Jin J. T., Ding L. X., Wang X. H., Liang Y., Wang Q. T. and J. Huang, 2014. A new nodavirus is associated with covert mortality disease of shrimp. J Gen Virol, 95: 2700-2709.

Zhang Z. H., Wu H. Z., Xiao J. F., Wang Q. Y., Liu Q. and Y. X. Zhang, 2012. Immune responses of zebrafish (Danio rerio) induced by bath-vaccination with a live attenuated Vibrio anguillarum vaccine candidate. Fish Shellfish Immunol, 33: 36-41.

Zhao H. X., Cao J. M., Wang A. L., Huang Y. H., Li G. L. and H. B. Lan, 2012. Effects of Dietary $\beta-1,3-$ Glucan on Expression of Immune-related Genes of Litopenaeus vannamei Exposed to Nitrite-N. J World Aquacult Soc, 43(3): 400-410. 